\title{
Complexes of Iron and Cobalt Porphyrins for Controlled Radical Polymerization of Methyl Methacrylate and Styrene
}

\author{
Yuri B. Monakov, ${ }^{\mathrm{a}}{ }^{@}$ Regina M. Islamova, ${ }^{\mathrm{a}}$ and Oscar I. Koifman ${ }^{\mathrm{b}}$ \\ ${ }^{a}$ Institute of Organic Chemistry of Ufa Scientific Centre of Russian Academy of Sciences, Ufa, 450054, Russia \\ ${ }^{b}$ Ivanovo State University of Chemistry and Technology, Ivanovo, 153000, Russia \\ @Corresponding authorE-mail: monakov@anrb.ru
}

\begin{abstract}
Radical polymerization of methyl methacrylate and styrene initiated by azo-bis-isobutironitrile or benzoyl peroxide in the presence of chlorine-containing complexes of Fe ${ }^{I I I}$ with 5,10,15,20-tetrakis-(3',5'-di-tert-butylphenyl)porphyrin, 5,10,15,20-tetrakis-(3'-butoxyphenyl)porphyrin or 5,15-bis(4'-tert-butylphenyl)-2,8,12,18-tetra(n-butyl)-3,7,13,17tetramethylporphyrin and acetate complexes of Co III with 5,10,15,20-tetrakis-(3',5'-di-tert-butylphenyl)porphyrin or 5,10,15,20-tetrakis-(3'-butoxyphenyl)porphyrin and complex of Co II with 5,15-bis(4'-tert-butylphenyl)-2,8,12,18tetra(n-butyl)-3,7,13,17-tetramethylporphyrin were investigated. The kinetic features of the process and molecular mass characteristics of polymers were studied. Feasible polymerization scheme was proposed.
\end{abstract}

Keywords: Controlled radical polymerization, iron and cobalt porphyrin complexes, methyl methacrylate, styrene, azo-bis-isobutironitrile, benzoyl peroxide, kinetic, molecular mass characteristics.

\section{Introduction}

The use of metal porphyrins in radical polymerization processes of vinyl monomers is of great interests. ${ }^{[1-9]}$ Catalytic chain transfer to the monomer and catalytic inhibition were discovered in the polymerization of metacrylates carried out in the presence of cobalt porphyrins by B.R. Smirnov. ${ }^{[1-4]}$ By B.B. Wayland and M. Fryd it was found that polymerization of acrylates initiated by cobalt complex of tetramesitylporphyrin proceeds per Stable Free Radical Polymerization. ${ }^{[6]}$ It was shown that $\mathrm{Al}^{\mathrm{III}}$ complexes of 5,10,15,20-tetraphenylporphyrin containing axial methyl, propanethyolate or enolate groups effectively initiate "living" radical polymerization of methacrylates and acrylates under ultraviolet irradiation. ${ }^{[7,8]}$ (Octaethylporphyrinato)rhodium(II) dimer has been also used as catalyst for controlled polymerization of acrylic esters under ultraviolet irradiation. ${ }^{[9]}$

The goal of this work was the study of radical polymerization of methyl methacrylate (MMA) and styrene

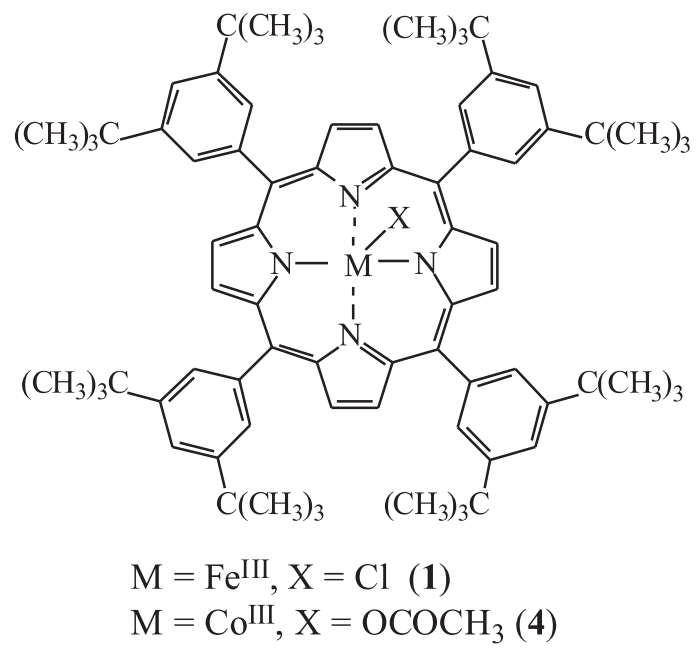

initiated by azo-bis-isobutironitrile (AIBN) or benzoyl peroxide in the presence of chlorine-containing complexes of $\mathrm{Fe}^{\mathrm{III}}$ with 5,10,15,20-tetrakis-(3',5'-di-tert-butylphenyl) porphyrin (1), 5,10,15,20-tetrakis-(3'-butoxyphenyl) porphyrin (2) or 5,15-bis(4'-tert-butylphenyl)-2,8,12,18tetra(n-butyl)-3,7,13,17-tetramethylporphyrin (3) which have different substituents in the porphyrin macrocycle, and in the presence of acetate complexes of 5,10,15,20-tetrakis-(3',5'di-tert-butylphenyl)porphyrin (4) or 5,10,15,20-tetrakis-(3'butoxyphenyl)porphyrin (5) and $\mathrm{Co}^{\mathrm{II}}$ complex of 5,15-bis(4'tert-butylphenyl)-2,8,12,18-tetra(n-butyl)-3,7,13,17tetramethylporphyrin (6).

\section{Experimental}

MMA (Fluka) and styrene (Fluka) were distilled two times under reduced pressure: b.p. $=48^{\circ} \mathrm{C}, \mathrm{P}=140 \mathrm{~mm} \mathrm{Hg}$ and b.p. $=$ $52^{\circ} \mathrm{C}, \mathrm{P}=27 \mathrm{~mm} \mathrm{Hg}$, correspondingly. AIBN and benzoyl peroxide were recrystallized three times from ethanol and dried at room 


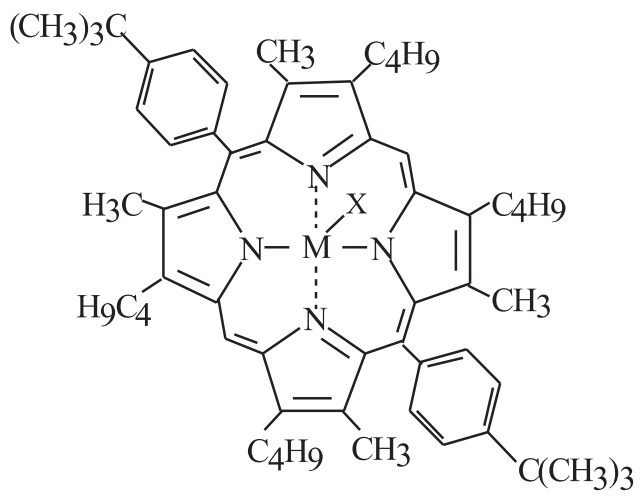

$\mathrm{M}=\mathrm{Fe} \mathrm{III}^{\mathrm{II}} \mathrm{X}=\mathrm{Cl}(\mathbf{3})$

$\mathrm{M}=\mathrm{Co}^{\mathrm{II}}(\mathbf{6})$

temperature under vacuum to a constant weight. Iron porphyrins $\mathbf{1}$, 2, 3 and cobalt porphyrins 4, 5, 6 were synthesized and purified as described earlier. ${ }^{[10]}$ Purity of substances was controlled by ${ }^{13} \mathrm{C}\left\{{ }^{1} \mathrm{H}\right\}$ NMR-spectroscopy.

Polymerization mixtures were placed into glass ampoules, degassed by three freeze-pump-thaw cycles to residual pressure of $1.3 \mathrm{~Pa}$, sealed and placed in an water (oil) bath at defined temperatures $\left( \pm 0 \cdot 1^{\circ} \mathrm{C}\right)$. After the predetermined intervals ampoules were cooled and unsealed. The obtained polymers were purified from residual initiator and additive by dissolving into acetone followed by precipitating into 10-15-fold excess methanol three times. The kinetic of bulk polymerization was studied by the dilatometric method. ${ }^{11]}$

Molecular weight characteristics were determined by gel permeation chromatography. Chromatography was performed on "Waters GPC 2000 System" chromatograph (eluent is tetrahydrofuran; flow rate is $0.5 \mathrm{ml} / \mathrm{min}$ ). Chromatographic columns were calibrated by polystyrene standards $\left(M_{\mathrm{w}} / M_{\mathrm{n}} \leq 1.2\right)$.

${ }^{1} \mathrm{H}$ NMR spectra were recorded in $\mathrm{CDCl}_{3}$ on a "Bruker AM300 " spectrometer at $25^{\circ} \mathrm{C}$. Tetramethylsilane was used as internal standard. Contents of syndio-, hetero- and isotactic fragments were determined using known method. ${ }^{[12]}$

Dynamic thermogravimetric analysis was performed on a "MOM" "Q-1000" derivatograph (heating rate is 5 degree/min, sample mass is $100 \mathrm{mg}$ ). Measurements were taken in air.

Physicochemical characteristics of purified distilled solvents (methanol, acetone, tetrahydrofuran, glycerin, deuterochloroform) satisfy the requirements. ${ }^{[13]}$

\section{Results and Discussion}

It was shown that the overall rate of the bulk polymerization of MMA initiated by AIBN in the presence of iron porphyrins 1,2 or 3 at $60^{\circ} \mathrm{C}$ decreases, gel-effect is suppressed and the conversion of monomer increases linearly on time (Figure 1). The greatest deceleration of polymerization is observed at the use of porphyrin $\mathbf{1}$ while the use of $\mathbf{3}$ leads to lesser deceleration. An increase in the iron porphyrin 3 concentration from 0.5 to $3.0 \mathrm{mmol} / \mathrm{l}$ (the concentration of AIBN amounts to $1.0 \mathrm{mmol} / \mathrm{l}$ ) facilitates a successive process reduction (Figure 1). Similar concentration dependences were obtained in the cases of the use of $\mathbf{2}$ or 3. Apparently, observed differences in the kinetic patterns of MMA polymerization initiated by AIBN in the presence of iron porphyrins are caused by the features of electron donating and spatial structures of substituents in porphyrin macrocycle. Thus, jointly butyl, methyl and tert-butylphenyl-

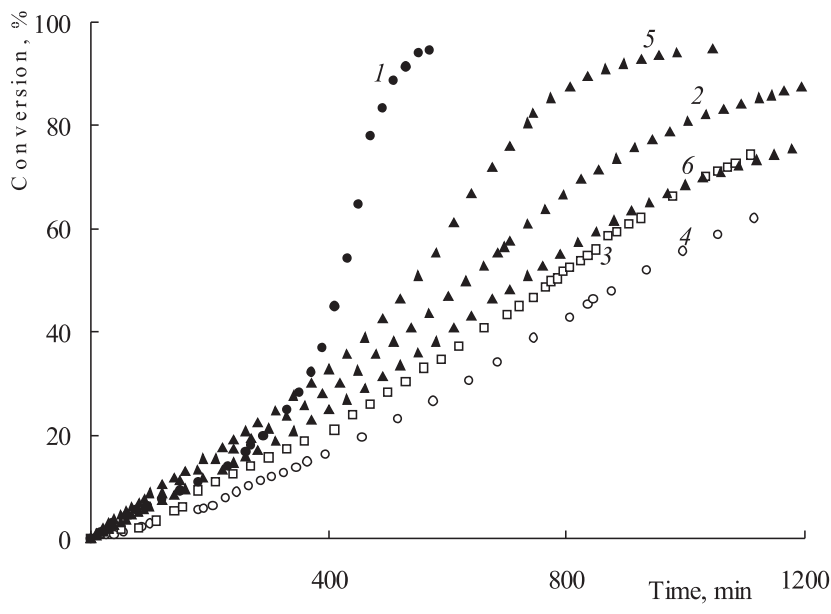

Figure 1. Conversion vs. MMA polymerization time at $60^{\circ} \mathrm{C}$ in the presence of AIBN (1), AIBN and porphyrins $3(2,5,6), 2$ (3) и 1 (4). The concentration of AIBN, $\mathbf{1}, 3$ is $1.0 \mathrm{mmol} / \mathrm{l}$; The concentration of 3 equils 0.5 (5); 1.0 (2) and 3.0 (6) mmol/1.

groups in porphyrin 3 have more electron-donating ability than tert-butylphenyl-groups and butoxyphenyl-groups in complexes 1 and 2. This can facilitate faster decomposition of porphyrin and macroradical adducts. But, as a whole, the influences of studied iron porphyrins on MMA radical polymerization are similar.

Polymethyl methacrylates (PMMA) synthesized in the presence of AIBN and iron porphyrins are transparent and have homogeneous structure without any defects and colors from light-brown to dark-brown according to iron porphyrin concentration. The molecular mass of obtained polymers is about 2-3 times lower than reference samples (which are synthesized solely with azo-initiator without metal complexes of porphyrin). The number-average molecular mass $\left(M_{\mathrm{n}}\right)$ of the polymers obtained in the presence of iron porphyrins $\mathbf{1}$, $\mathbf{2}$ or $\mathbf{3}$ depends linearly on monomer conversion beginning from $10 \%$ conversion (Figure 2). It should be noted that $M_{\mathrm{n}}$-conversion curves intercepts on an ordinate axis at 350000 - 500000. Apparently it is caused by side reactions in polymerization system which will be discussed below.

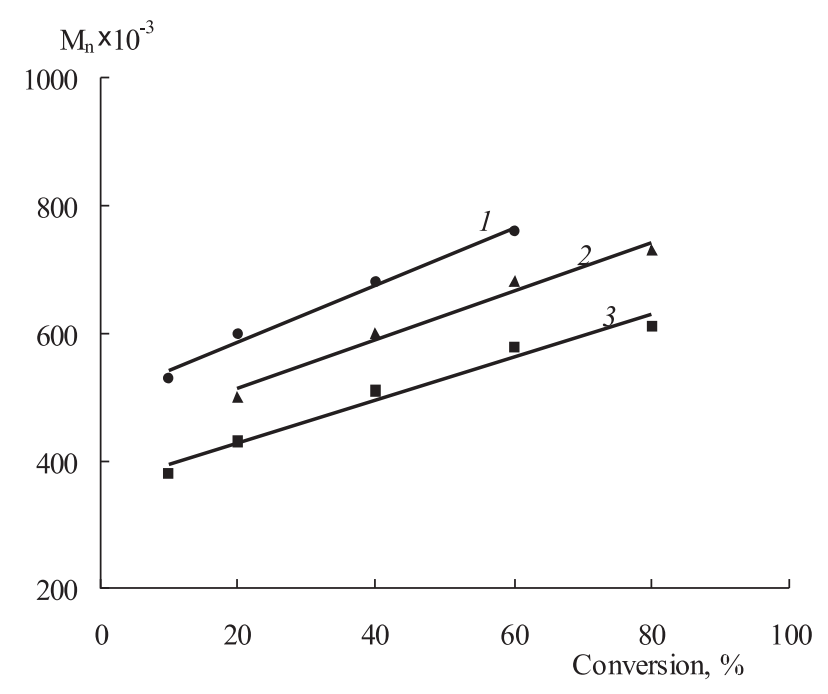

Figure 2. $M_{n}$ of PMMA obtained in the presence of AIBN (1.0 $\mathrm{mmol} / \mathrm{l})$ and porphyrins 1 (1), 2 (2) and 3 (3) $(1.0 \mathrm{mmol} / \mathrm{l}) v \mathrm{~s}$. monomer conversion. Polymerization temperature is $60^{\circ} \mathrm{C}$. 
The polydispersity coefficients $\left(M_{\mathrm{w}} / M_{\mathrm{n}}\right)$ of PMMA obtained in the presence of iron porphyrins decrease in comparison to the reference samples and remain almost unchanged during the polymerization process (Figure 3 ). In the case when porphyrin 1 is used $M_{\mathrm{w}} / M_{\mathrm{n}}$ amounts to $1.60 \div 1.75$, porphyrin $2-1.50 \div 1.65$ and porphyrin $3-1.40 \div 1.50$. Molecular weight distribution (MWD) curves for polymers synthesized in the presence of iron porphyrin $\mathbf{1}$ (as well as in the presence of additives $\mathbf{2}$ and $\mathbf{3}$ ) are of the unimodal type and are shifted to the higher molecular masses with conversion (Figure 4).

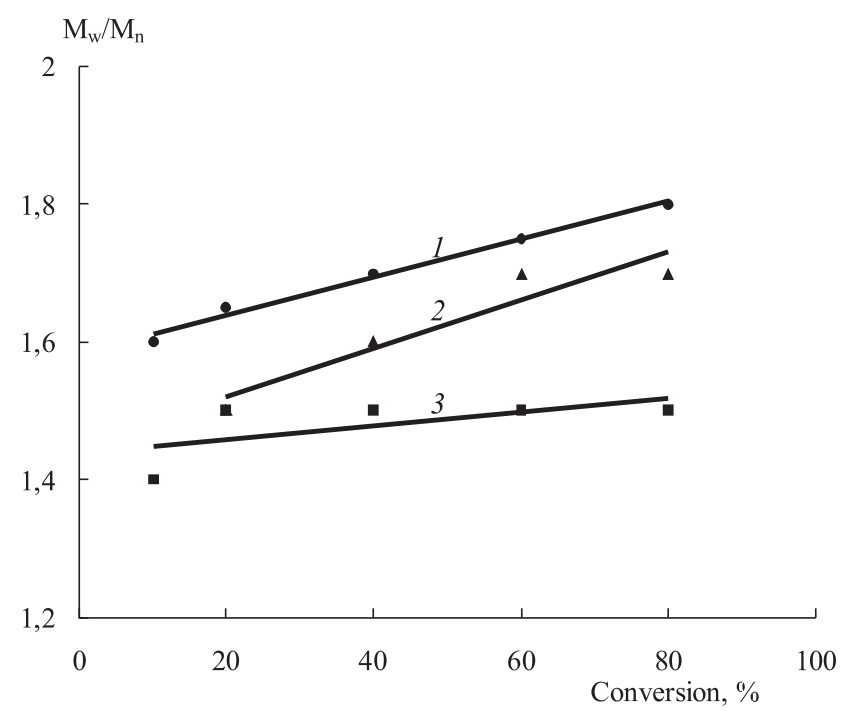

Figure 3. $M_{\mathrm{w}} / M_{\mathrm{n}} v s$. monomer conversion at MMA polymerization in the presence of $\operatorname{AIBN}(1.0 \mathrm{mmo} / \mathrm{l})$ and porphyrins 1 (1), 2 (2) и 3 (3) $(1.0 \mathrm{mmo} / \mathrm{l})$. Polymerization temperature is $60^{\circ} \mathrm{C}$.

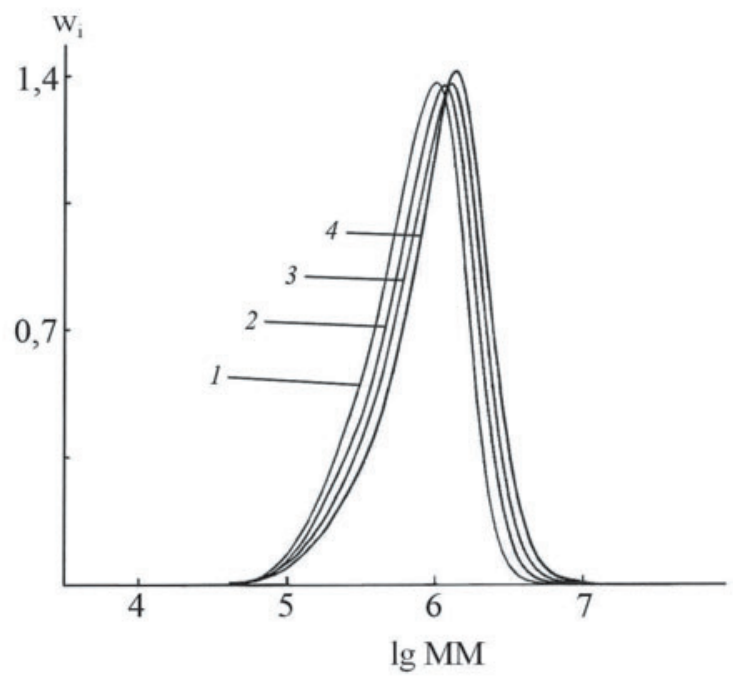

Figure 4. MWD curves of PMMA obtained in the presence of $\operatorname{AIBN}(1.0 \mathrm{mmol} / \mathrm{l})$ and porphyrin $1(1.0 \mathrm{mmol} / \mathrm{l})$ at $60^{\circ} \mathrm{C}$. Monomer conversion, \%: 10 (1), 20 (2), 40 (3), 60 (4). $w_{i}$ - mass fraction of macromolecules with certain molecular mass (MM).

The content of syndiotactic fragments in the chains of PMMA obtained in the presence of iron porphyrins at different conversions at $60^{\circ} \mathrm{C}$ increases by $3-10 \%$, the content of isotactic fragments amounts to $3-5 \%$ (Table 1). Decomposition temperature (d.t.) increases by about 10 $54^{\circ} \mathrm{C}$ and depends on iron porphyrin. The greatest influence on stereoregularity (the content of syndiotactic fragments
Table 1. Microstructure and decomposition temperature of PMMA obtained in the presence of iron porphyrins $(1.0 \mathrm{mmol} / \mathrm{l})$ and AIBN $(1.0 \mathrm{mmol} / \mathrm{l})$. Process temperature is $60^{\circ} \mathrm{C}$.

\begin{tabular}{cccccc}
\hline \multirow{2}{*}{ Porphyrin } & $\begin{array}{c}\text { Conversion, } \\
\%\end{array}$ & \multicolumn{3}{c}{ Content of triads, \% } & d.t., \\
\cline { 3 - 5 } & 10 & 55 & 43 & 2 & 224 \\
\hline- & 20 & 59 & 38 & 3 & 250 \\
\hline \multirow{2}{*}{$\mathbf{1}$} & 40 & 63 & 34 & 3 & 252 \\
& 60 & 58 & 37 & 5 & 247 \\
\hline \multirow{2}{*}{$\mathbf{2}$} & 20 & 62 & 33 & 5 & 276 \\
& 40 & 65 & 31 & 4 & 277 \\
& 60 & 64 & 32 & 4 & 278 \\
\hline \multirow{3}{*}{3} & 10 & 61 & 35 & 4 & 261 \\
& 20 & 59 & 36 & 5 & - \\
& 40 & 61 & 35 & 4 & 235 \\
& 60 & 59 & 36 & 5 & - \\
& 80 & 59 & 36 & 5 & - \\
\hline
\end{tabular}

increases by $8-10 \%$ ) and on thermostability of polymers (d.t. increases by $52-54^{\circ} \mathrm{C}$ ) is observed in the case of porphyrin 2 . In the derivative thermogravimetry curves (DTG) for PMMA obtained in the presence of 2 the low-temperature peak at 247$248^{\circ} \mathrm{C}$ (Figure 5) vanishes. Decomposition of PMMA occurs rapidly in narrow temperature interval $\left(270-380^{\circ} \mathrm{C}\right)$ with heat

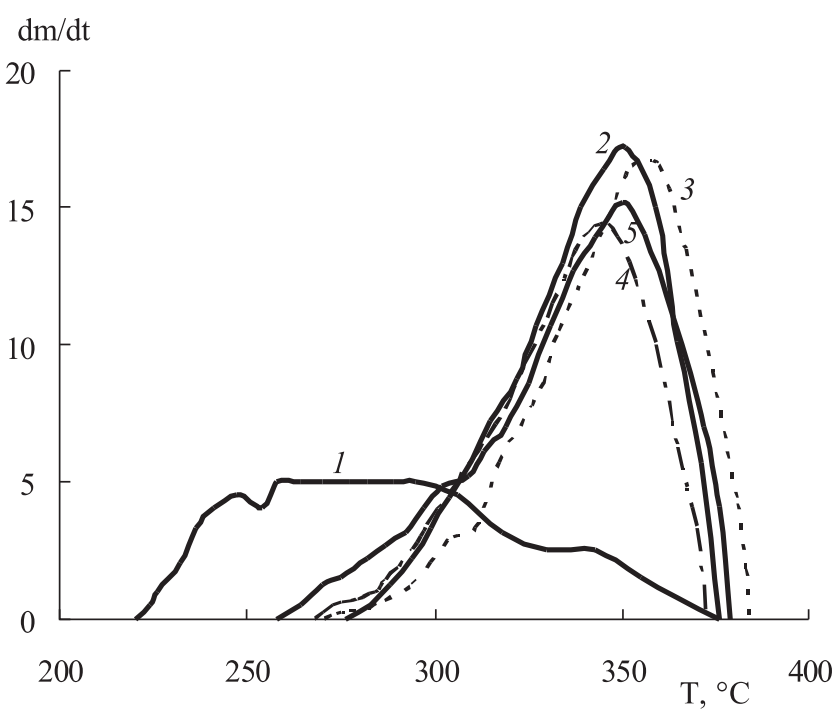

Figure 5. DTG curves of PMMA synthesized at $60^{\circ} \mathrm{C}$ in the presence of AIBN (1.0 mmol/l) (1), AIBN and porphyrin 2 (1.0 mmol/l) (2-5). Monomer conversion, \%: 20 (1, 2); 40 (3); 60 (4) and $80(5)$.

absorption. Apparently porphyrins affect low-temperature stage of polymer destruction. The thermostability increase of PMMA synthesized in the presence of iron porphyrins may be caused, on the one hand, by the increase in the content of syndiotactic fragments as a result of more regulated addition of monomer to macroradical and, on the other hand, by the formation of the more stable fragments of metalloporphyrins at polymer chain ends.

The data obtained are proof that iron porphyrins 1, 2 and $\mathbf{3}$ control both stereoregularity of macrochains and molecular 

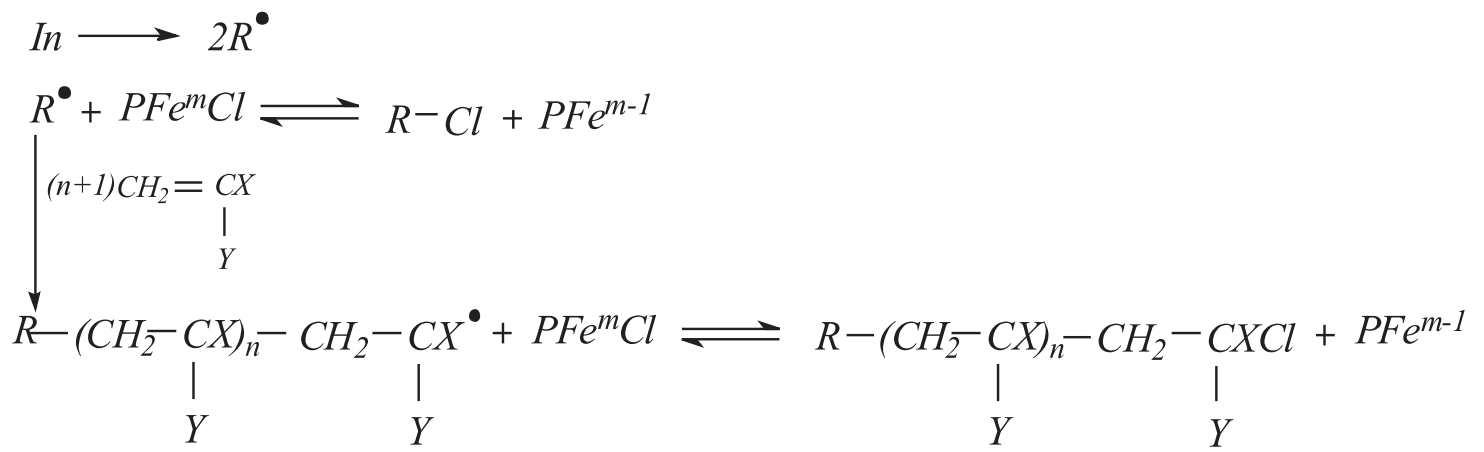

Scheme 1.

mass distribution. The revival of macromolecules can probably occur via the reversible atom transfer mechanism - RATRP ${ }^{[14,15]}$ (Scheme 1).

It should be noted that along with "living" macromolecules there are "dead" macromolecules due to bimolecular termination of macroradicals in simultaneous free-radical polymerization. Therefore $M_{\mathrm{n}}$-conversion curve intercepts on ordinate axis (Figure 2).

It is known that acryl and methacryl monomers show higher activity than styrene in polymerization processes. [11] Thus, the bulk polymerization of styrene initiated by AIBN in the presence of iron porphyrin at $100^{\circ} \mathrm{C}$ occurs practically in the same manner as the process without metal porphyrin. Apparently, differences in the kinetic features of MMA or styrene polymerization in the presence of chlorinecontaining iron porphyrins may be due to different ability of these unsaturated monomers to coordinate with transition metal in porphyrin. Nevertheless general trend of MMA or styrene polymerization initiated by AIBN is the same and the overall mechanism is RATRP, which is evidenced by the molecular mass characteristics of polystyrene synthesized in the presence of iron porphyrin 3 , namely, a linear increase of $M_{\mathrm{n}}$ on conversion and relatively narrow MWD (Figure 6).

If benzoyl peroxide is used as an initiator in the polymerization of MMA, the addition of iron porphyrins leads to essential decrease in the process rate (Figure 6). As

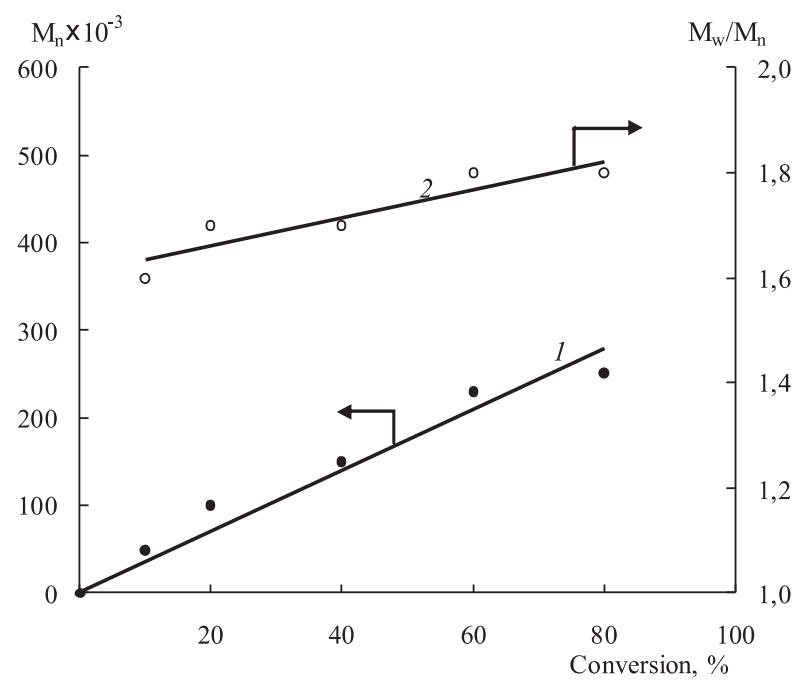

Figure 6. $M_{\mathrm{n}}(1)$ and $M_{\mathrm{w}} / M_{\mathrm{n}}$ (2) of polystyrene obtained in the presence of AIBN $(1.0 \mathrm{mmol} / \mathrm{l})$ and porphyrin $3(1.0 \mathrm{mmol} / \mathrm{l}) \mathrm{vs}$. monomer conversion. Polymerization temperature is $100^{\circ} \mathrm{C}$. was mentioned in ${ }^{[14,16]}$ polymerization initiated by peroxides behaves quite differently from "living" polymerization due to complexation of metalloorganic compounds with initiator. The nature of monomer, which plays an important role, should be taken into consideration as well. It is not excepted that considerable deceleration of MMA polymerization is caused by participation of monomer in complexation of peroxide and iron porphyrin. The results of styrene polymerization investigation proof that assumption. Thus, the rate of the benzoyl peroxide-initiated styrene polymerization in the presence of iron porphyrins decreases also, but not as fast as in the case of MMA polymerization (Figure 7).

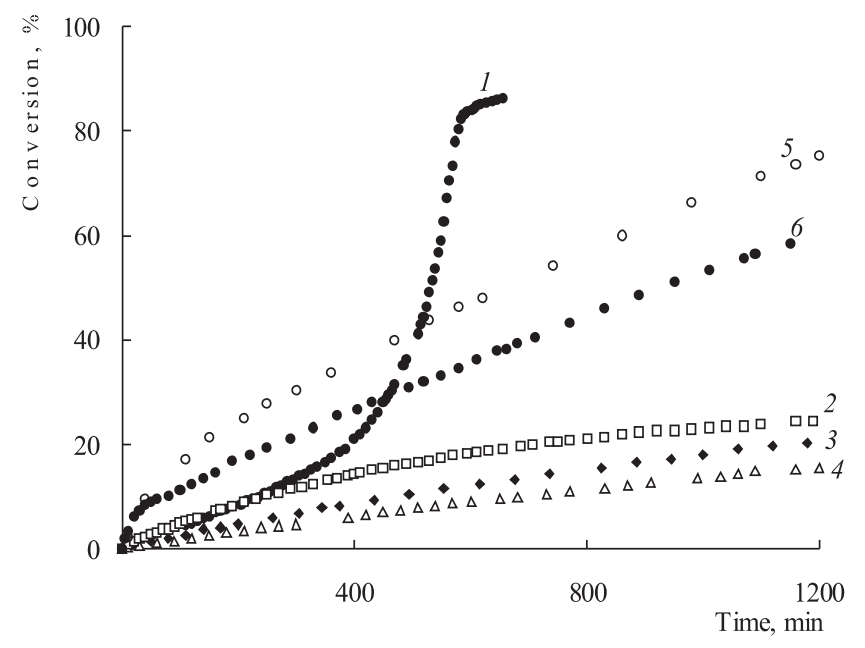

Figure 7. Conversion $v s$. MMA polymerization time at $60^{\circ} \mathrm{C}(1-4)$ and styrene at $100^{\circ} \mathrm{C}(5,6)$ in the presence of benzoyl peroxide $(1$, $5)$, benzoyl peroxide $(1.0 \mathrm{mmol} / \mathrm{l})$ and porphyrins $(1.0 \mathrm{mmol} / \mathrm{l}) 3$ (2, 6), 2 (3) and 1 (4).

Radical polymerization of MMA initiated by AIBN in the presence of cobalt porphyrins 4,5 or 6 at $60^{\circ} \mathrm{C}$ was studied. According to the influence on the overall polymerization the rate cobalt porphyrins could be placed in following order: $6>5>4$ (Figure 8 ). In the case of iron porphyrins similar order is observed: $\mathbf{3}>\mathbf{2}>\mathbf{1}$ (Figure 1). Cobalt porphyrins decelerate polymerization greater than iron porphyrins. Thus, at the addition of cobalt porphyrins the ultimate yield of PMMA did not exceed $40 \%$ for 20 hours (Figure 8).

If benzoyl peroxide is used as an initiator the addition of studied cobalt porphyrins (the concentration of additive 


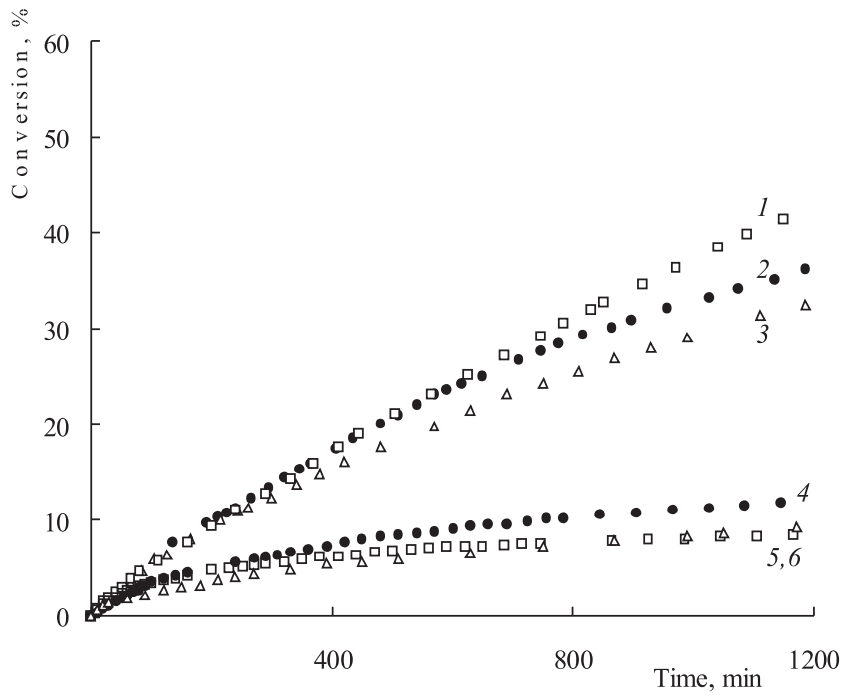

Figure 8. Conversion vs. MMA polymerization time at $60^{\circ} \mathrm{C}$ in the presence of AIBN and porphyrins 4 (3), 5 (2) and 6 (1); benzoyl peroxide $(1.0 \mathrm{mmol} / \mathrm{l})$ and porphyrins $(1.0 \mathrm{mmol} / \mathrm{l}) \mathbf{4}(5)$, 5 (4) and 6 (6).

amounts to $1.0 \mathrm{mmol} / \mathrm{l})$ leads to stoppage of MMA polymerization (Figure 8), however moderate acceleration of the process at initial stages is observed (Table 1). It was mentioned in ${ }^{[4]}$ that peroxides can cause "poisoning" of cobalt porphyrins as chain transfer catalysts. Studies were carried out using tetramethylether of hematoporphyrin mainly. In the case of porphyrin $\mathbf{4}$ "poisoning” of catalyst was not observed, which is evidenced by the decrease in the auto acceleration, the decrease of molecular masses of obtained PMMA and the increase of initial polymerization rate.

Table 2. Kinetic features of MMA polymerization and PMMA molecular weight characteristics obtained in the presence of benzoyl peroxide $(1.0 \mathrm{mmol} / \mathrm{l})$ and cobalt porphyrin 4 at $60^{\circ} \mathrm{C}$. Monomer conversion is $5-7 \%$.

\begin{tabular}{cccc}
\hline $\begin{array}{c}\text { Concentration of 4, } \\
\text { mol/1 }\end{array}$ & $\begin{array}{c}{ }^{*} W_{0} \times 10^{3}, \\
\mathrm{~mol} /(1 \times \min )\end{array}$ & $M_{\mathrm{n}} \times 10^{-3}$ & $M_{\mathrm{w}} / M_{\mathrm{n}}$ \\
\hline 0 & 4.0 & 980 & 2.0 \\
0.25 & 8.0 & 500 & 2.3 \\
0.50 & 8.3 & 35 & 3.0 \\
1.00 & 9.2 & \multicolumn{2}{c}{ Low molecular } \\
& \multicolumn{3}{c}{ products } \\
\hline
\end{tabular}

${ }^{*} W_{0}$ - polymerization rate at the initial stages.

$M_{\mathrm{n}}$ value of PMMA synthesized in the presence of benzoyl peroxide and cobalt porphyrin $\mathbf{4}$ increases linearly on monomer conversion at all studied porphyrin concentration, the polydispersity coefficients amount to 2.0-3.0 (Table 2). MWD curves for polymers obtained at the concentration of cobalt porphyrin 4 of $0.25 \mathrm{mmol} / \mathrm{l}$ are of the unimodal type and become broader at high conversions. MWD curves for PMMA synthesized at $0.5 \mathrm{mmol} / 1$ of cobalt porphyrin 4 are of the bimodal type and become narrower in the course of polymerization (Figure 9). Apparently, the influence of cobalt porphyrin on molecular mass characteristics of obtained polymers increases at concentration of cobalt porphyrin of $0.5 \mathrm{mmol} / \mathrm{l}$ and higher.

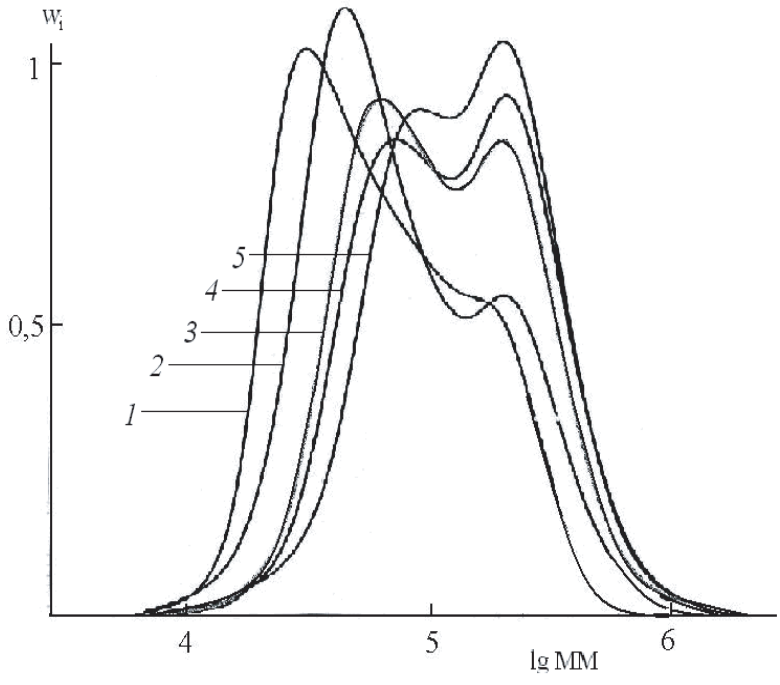

Figure 9. MWD curves of PMMA obtained in the presence of benzoyl peroxide $(1.0 \mathrm{mmol} / \mathrm{l})$ and porphyrin $4(0.5 \mathrm{mmol} / \mathrm{l})$. Monomer conversion, \%: 3 (1), 8 (2), 10 (3), 20 (4), 60 (5). Polymerization temperature is $60^{\circ} \mathrm{C} . w_{\mathrm{i}}$ - mass fraction of macromolecules with certain molecular mass (MM).

\section{Conclusions}

On the basis of experimental data it can be concluded that in MMA and styrene polymerization initiated by azo-initiator in the presence of iron porphyrins of different structure, features of controlled radical polymerization via RATRP are observed. Along with the regulation of MWD the iron porphyrins affect stereo regularity of synthesized polymers, i.e. the content of syndiotactic fragments in the chains of PMMA increases by $10 \%$. Specific feature is inhibition of benzoyl peroxide-initiated polymerization of MMA in the presence of iron porphyrins (while the polymerization of styrene occurs to high monomer conversion at the same condition), which is caused probably by participation of monomer (MMA) in the complexation of peroxide and additive. Activities of porphyrins are affected by features of electron donating and spatial structures of substitutes in porphyrin cycle, i.e. more electron-donating groups facilitate decomposition of porphyrin and macroradical adducts.

Polymerization carried out in the presence of cobalt porphyrin and azo- or peroxide initiator tends to complexradical process ${ }^{[17-19]}$ complicated by chain transfer reaction on monomer. In the benzoyl peroxide-initiated polymerization the complexation processes of initiator and cobalt porphyrin are possible.

\section{References}

1. Smirnov B.R., Bel'govskii I.M., Ponomarev G.V., Marchenko A.P., Enikolopyan N.S. Dokl. Akad. Nauk SSSR 1980, 254, 127-130 (in Russ.)

2. Smirnov B.R., Plotnikov V.D., Ozerkovskii B.V., Roschupkin V.P., Enikolopyan N.S. Vysokomol. Soedin. 1981, 23, 25882595 (in Russ.).

3. Smirnov B.R., Pushchaeva L.M., Plotnikov V.D. Vysokomol. Soedin. 1989, 37, 2378-2384 (in Russ.).

4. Porfiriny: Struktura, Svoistva, Sintez (Porphyrins: Structure, Properties, Synthesis) (Enikolopyan N.S., Ed.) Moscow, Nauka, 1985, 333 p. (in Russ.). 
Iron and Cobalt Porphyrins for Controlled Radical Polimerization

5. Monakov Yu.B., Koifman O.I., Islamova R.M., Nasretdinova R.N., Ageeva T.A. Uspekhi Khimii, 2007, 5, 293. (in Russ.).

6. Lu Zh., Fryd M., Wayland B. Macromolecules 2004, 37, 26862687.

7. Kuroki M., Aida T., Inoue S. J. Amer. Chem. Soc. 1987, 109, 4737-4738.

8. Hosokawa Y., Kuroki M., Aida T., Inoue S. Macromolecules 1991, 24, 824-829.

9. Wayland B.B., Poszmik G., Fryd M. Organometallics 1992, 11, 3534-3542.

10. Smith K.M. Porphyrins and Metalloporphyrins. AmsterdamLondon-New York, Elsevier, 1975.

11. Gladyshev G.P. Polimerizatsiya Vinilovykh Monomerov (Polymerization of Vinyl Monomers), Alma-Ata, Nauka, 1964. 322 p. (in Russ.).

12. Ferguson R.C. Div. Polym. Prepr. (Am. Chem. Soc.) 1985, 6, 182-183.
13. Gordon A.J., Ford R.A. The Chemist's Companion. A Handbook of Practical Data, Techniques and References. New York, A Wiley-Interscience Publication John Wiley and Sons, 1972, 542 p.

14. Matyjaszewski K., Xia J. Chem. Rev. 2001, 101, 2921-2990.

15. Yakimanskii A.V. Vysokomolek. Soed. 2005, 47, 1241-1301. (in Russ.).

16. Matyjaszewski K., Wei M., Xia J., McDermott N. E. Macromolecules 1997, 30, 8161-8164.

17. Kabanov V.A., Zubov V.P., Semchikov Yu.D. Complex-Radical Polymerization. Moscow, Chemistry, 1987, 255 p. (in Russ.).

18. Islamova R.M., Sadykova G.R., Puzin Yu.I., Spirikhin L.V., Kraikin V.A., Monakov Yu.B. Polymer Science. Ser. B 50, 128-133.

19. Islamova R.M., Puzin Yu.I., Yumagulova R.Kh., Fatykhov A.A., Parfenova L.V., Dzhemilev U.M., Monakov Yu.B. Polymer Science. Ser. B 2006, 48, 712-716.

Received 15.05.2009 Accepted 01.06.2009 